\title{
GESTÃO DOS HERDEIROS OU DE PROFISSIONAIS NAS EMPRESAS FAMILIARES: O CASO DA PERDIGÃO*
}

\author{
Armando João Dalla Costa ${ }^{* *}$
}

\begin{abstract}
RESUMO Este texto visa a analisar a história da Perdigão, da sua origem, em meados da década de 1930, até hoje. O artigo parte do estudo da passagem das empresas tradicionais e familiares para as firmas modernas, com administração profissional. A Perdigão começou atuando em dois produtos e em uma única região de onde, após três décadas, cresceu, diversificou as áreas de atuação e a gama de produtos, ocupando o território nacional, tanto com unidades industriais quanto com filiais comerciais. Na seqüência, estuda-se a passagem do poder da segunda para a terceira geração, quando enfrentou dificuldades financeiras e administrativas e foi vendida pelos herdeiros. Ao deixar de ser uma empresa familiar e profissionalizar sua gestão, a Perdigão retomou o caminho do crescimento, da inovação e da disputa pelo mercado nacional e pelas exportações.
\end{abstract}

Palavras-chave: perdigão; empresa familiar; administração profissionalizada; agroindústria; avicultura

Código JEL: L, L22, L66

\section{THE INHERITY OR THE PROFESSIONALLY MANAGERS \\ IN THE FAMILY COMPANIES: THE PERDIGÃO'S CASE}

ABSTRACT This paper aims analysing the history of Perdigão, from its foundation in the mid 1930s until nowdays. The main concern is related to how traditional and family companies can become modern and professionally managed. That company started by operating with only two products in a region, from where, three decades

* Artigo recebido em 24 de outubro de 2005 e aprovado em 12 de dezembro de 2006.

** Doutor pela Université de Paris III (Sorbonne Nouvelle). Professor do Programa de Pós-graduação em Desenvolvimento Econômico e coordenador do Núcleo de Pesquisa em Economia Empresarial na UFPR (www.empresas.ufpr.br),e-mail: ajdcosta@ufpr.brou ajdcosta@uol.com.br 
later, expanded and diversified its business and range of products, towards the Brazilian domestic market through the installation of new industrial and commercial branches. Subsequently, the transition of power from the second to third generation, when financial and administrative difficulties emerged, leading to its sale by the heirs, is analysed in this paper. As it was no longer a family company, and its management became more professional, Perdigão returned to a path of growth, innovation and ability to compete in national as well as foreign markets.

Key words: family company; professional management; agoindustry; poultry 


\section{INTRODUÇÃO}

A Perdigão, uma das maiores companhias de alimentos da América Latina, comemorou em 2004 seu $70^{\circ}$ aniversário. Durante estes 70 anos tem contribuído de forma expressiva para o desenvolvimento da economia nacional, para o bom desempenho das exportações e para o fortalecimento da imagem do Brasil no mercado internacional. Hoje está entre as grandes empregadoras do País, com 30.943 funcionários, mantém parceria com cerca de 5.800 produtores integrados e exporta seus produtos para mais de 90 países.

É com esse discurso que o site ${ }^{1}$ oficial da empresa inicia sua apresentação. A Perdigão, junto com Sadia, Ceval, Chapecó, Aurora, Frangosul, Avipal, para citar as maiores, todas originárias de Santa Catarina e do Rio Grande do Sul, foi responsável pela transformação de um dos setores da economia brasileira contemporânea. Em 1970, a produção avícola era de 217 mil toneladas, o preço médio do quilo de carne de frango no varejo estava em U\$ 4,05 e o consumo por habitante/ano era de 2,3 quilos (Dalla Costa, 2000: 1).

Graças às inovações tecnológicas e de organização do trabalho, introduzidas por essas e demais empresas do setor, a produção avícola deixou de ser uma atividade familiar e artesanal para tornar-se um dos setores de ponta em tecnologia e produção em nível nacional. As empresas, por sua vez, passaram de pequenas e artesanais para grandes conglomerados industriais, presentes em todo o País e exportando, em 2004, U\$ 2,6 bilhões.

Nesse mesmo ano, a produção brasileira foi de 8,4 milhões de toneladas, e cerca de seis milhões destinaram-se ao mercado interno, correspondendo a 33,5 quilos por habitante/ano. O preço médio do quilo no varejo esteve abaixo de um dólar, e o Brasil tornou-se o maior exportador mundial do produto, superando os EUA.

A Perdigão, desde a década de 1970, ocupou o segundo lugar tanto na produção nacional quanto nas exportações. Atualmente, ocupa essa mesma posição não só no abate, mas também na industrialização e vendas de carnes de aves e suínos. O objetivo do texto é resgatar sua história e analisar a passagem da gestão familiar para a profissional. Para atingir tal objetivo, o suporte teórico em história das firmas está baseado nos textos de Chandler (1972, 1988, 1992), que analisa o papel e o funcionamento das empresas familiares e tradicionais e a passagem desse modelo para outro que ele de- 
signa como "empresa moderna". No que se refere à passagem do poder entre as gerações, Gersick et al. (1998) apresentam as principais teorias e cases.

A partir das idéias desses autores, buscou-se escrever a história da empresa, que, em 1934, iniciou suas atividades no oeste de Santa Catarina. O estudo apresenta os principais passos da Perdigão, administrada por representantes das famílias fundadoras (Brandalise, Ponzoni e Bonato), com destaque para o papel que desempenhou a segunda geração.

Em seguida, volta-se para a diversificação de atividades e a trajetória da empresa na conquista do mercado nacional. Nesse caso houve a instalação de unidades industriais em outras regiões, assim como o desenvolvimento de uma rede de filiais comerciais próprias que fazem chegar seus produtos a todo o território nacional.

Na segunda parte, o trabalho analisa as dificuldades administrativo-financeiras pelas quais passou a Perdigão por ocasião da morte de Saul Brandalise, durante muitos anos responsável pelo desenvolvimento do grupo, no início da década de 1990. A firma foi vendida e passou por um processo de reestruturação e mudanças, garantindo sua continuidade e a volta ao crescimento.

\section{O PAPEL DOS DIRIGENTES E ACIONISTAS NA ADMINISTRAÇÃO DA EMPRESA FAMILIAR}

Antes de surgirem as empresas capitalistas, continuando com uma tradição da Idade Média, a maior parte das mercadorias era produzida pelas próprias famílias, no interior das fazendas, de forma artesanal ou nas manufaturas. A maior parte da população vivia no campo, ou seja, no mesmo local da produção. Chandler (1988: 59) estima que, em 1790, 90\% da população ativa dos Estados Unidos era representada por agricultores e morava na área rural. No início do século XIX, a propriedade familiar que praticava a cultura para o mercado produzia igualmente sua própria alimentação, artigos manufaturados, móveis, sabão, velas, couro, tecido e vestes.

As empresas surgiram naquele país, segundo o autor, na medida em que foi se expandindo o mercado consumidor e para atender à demanda da população urbana. No Brasil ocorreu fenômeno semelhante. O primeiro surto industrial está ligado à expansão da cafeicultura, à chegada de imigrantes 
estrangeiros e à formação do primeiro mercado interno com o início da urbanização (Dean, 1971). O mesmo fenômeno registrou-se nas demais regiões que se industrializaram a partir da ocupação territorial e da produção local. No caso do oeste catarinense, onde iniciou a Perdigão, a ocupação aconteceu a partir de 1920. Em um primeiro momento, os colonos produziam quase tudo em suas propriedades. Em seguida veio o comércio, que ligava a região a São Paulo e depois as primeiras agroindústrias que beneficiavam os produtos agrícolas e abatiam os animais produzidos no local. ${ }^{2}$

Foi nessa primeira fase industrial que a Perdigão iniciou suas atividades com um moinho de trigo, uma loja de "secos e molhados" e um abatedor de suínos. Constituiu-se como empresa familiar, com as mesmas características apontadas por Chandler. Para esse autor, a empresa familiar

era formada por uma única entidade. Nela um ou vários proprietários dirigiam uma casa comercial, uma fábrica, um banco ou um serviço de transportes a partir de um único escritório. Em geral este tipo de empresa desempenhava uma única função econômica, para uma só categoria de produtos e numa determinada região geográfica. (Chandler, 1988: 3)

À medida que o mercado cresceu, aumentaram o volume e a diversificação das mercadorias, exigindo uma evolução constante das empresas. Para Chandler, a "empresa moderna" substituiu a "familiar". Essa passagem aconteceu, nos EUA, entre o final do século XIX e o início do seguinte. O que passou a caracterizar a empresa moderna foi, por um lado, o fato de ela possuir numerosas unidades operacionais e, por outro, ser dirigida por uma hierarquia de profissionais assalariados.

No interior da empresa moderna, cada divisão conta com sua própria administração. Cada uma é gerenciada por um dirigente, tendo sua própria contabilidade, que pode ser verificada independentemente daquela da empresa como um todo. Cada unidade industrial poderia, teoricamente, funcionar como uma firma independente.

Antes do surgimento da empresa moderna, os proprietários dirigiam e os gerentes eram os proprietários. Com a consolidação de tais empresas, em função de seu tamanho, diversidade da produção e profissionalização dos quadros dirigentes, houve uma separação entre a propriedade e a gestão. Outro fator que contribuiu para separar propriedade e gestão foi a necessidade de capitais externos para o crescimento e a expansão das atividades. 
Uma vez que os bancos e/ou demais acionistas investiam capital, exigiam também um lugar no conselho de administração.

Ao se consolidarem em seus cargos, esses dirigentes preferiam linhas de ação de longo prazo, favorecendo mais a estabilidade e o crescimento das empresas do que a maximização dos lucros e dividendos de curto prazo. Para eles, a continuidade da firma na qual trabalhavam era um elemento fundamental na própria carreira. Seu primeiro objetivo era assegurar seu bom funcionamento. Estavam muito mais dispostos que os proprietários a reduzir e mesmo eliminar os dividendos, se necessário, para garantir a continuidade da empresa.

Para melhor compreender a trajetória da Perdigão, enquanto se manteve nas mãos das famílias fundadoras, buscou-se auxílio nos autores que trabalham com a idéia do modelo de "três círculos" da empresa familiar, envolvendo família, propriedade e gestão (Gersick et al., 1998). Estes descrevem o desenvolvimento das empresas familiares ligando-o ao eixo família, empresa e propriedade das ações.

Em sua análise, o eixo de desenvolvimento da propriedade passa por três estágios principais. Primeiro, o do proprietário controlador, responsável pela fundação, controle de todas as ações, administração e primeiro desenvolvimento da empresa. Em seguida, surge a sociedade entre irmãos, quando gradativamente os filhos e/ou genros assumem cargos importantes na administração. Depois, dá-se a passagem para o "consórcio de primos", no qual a direção passa a ser exercida pela terceira geração da família. ${ }^{3}$

\section{A PERDIGÃo COMO CASO TíPICO dE EVOLUÇÃo NAS EMPRESAS FAMILIARES}

A ocupação do oeste catarinense foi fruto do deslocamento dos colonos, descendentes de imigrantes italianos e alemães do Rio Grande do Sul que buscavam novas terras para se estabelecer. O Vale do Rio do Peixe, onde iniciou a Perdigão, foi ocupado somente a partir de 1916, com o fim da Guerra do Contestado, ${ }^{4}$ e após muita negociação, no final da qual as terras da região conflituosa passaram a pertencer ao Estado de Santa Catarina.

A antiga região do Contestado interessou aos imigrantes porque, além de as terras serem próprias para o cultivo de vários gêneros alimentícios, elas 
eram vizinhas da estrada de ferro recém-construída, ${ }^{5}$ o que facilitaria o comércio dos produtos regionais.

Foi nesse fluxo de imigrantes vindos do Rio Grande do Sul que as famílias fundadoras da Perdigão chegaram à região. Os irmãos Angelo e Pedro Ponzoni, Giovanni e Ricardo Brandalise chegaram ao Vale do Rio do Peixe e adquiriram terras à beira da ferrovia, no atual município de Tanguá. Ricardo Brandalise comprou outra área na atual cidade de Videira, onde se estabeleceu com a família, dedicando-se à lavoura.

Em 1920, além da atividade agrícola, a família Brandalise construiu um pequeno moinho de trigo. A partir daí dividia-se entre a propriedade de São Roque, onde continuava a cultivar cereais e uvas, e o moinho. Em 1923, parte dos Brandalise mudou-se para a vila de Perdizes (atual Videira), indo trabalhar com loja de "Secos e Molhados".

Por seu lado, os irmãos Ponzoni também desenvolviam seus empreendimentos: uma casa de compra e venda por atacado e um pequeno abatedouro de suínos, com industrialização dos derivados, principalmente a produção de banha.

Em 1934, depois de muita negociação, as duas famílias resolveram associar seus capitais formando a sociedade Ponzoni, Brandalize \& Cia. Tornaram-se sócios Ângelo e Pedro Ponzoni, com 37,5\% do capital, e André David, Arthur, Guilherme, Abrão e Saul Brandalise, com 62,5\% (Tassara e Scapin, 1996: 36). Logo depois, Saul Brandalise desligou-se dos negócios da família, indo trabalhar como contador nos escritórios da firma Floriani, Bonato \& Cia.

Em 1937, aconteceu nova reestruturação na firma, quando, para ampliar sua área de comércio, associou-se à Floriani, Bonato \& Cia. A nova empresa estendia sua área de atuação às atuais cidades de Iomerê, Arroio Trinta, Bom Sucesso, Tangará, Capinzal, Herval d'Oeste, Joaçaba e Pinheiro Preto.

A década de 1930 foi significativa para as famílias do empreendimento, tanto do ponto de vista familiar quanto do profissional. Saul Brandalise, que viria a ser um dos principais dirigentes da empresa, casou-se em 1937 com Elejalde Formighieri. ${ }^{6}$ No mesmo ano, pelo falecimento do pai, ele e os irmãos assumiram definitivamente o controle dos negócios.

No início de 1939, a Frey \& Kellermann, empresa de abate de suínos atuando há cerca de 10 anos no Vale do Rio do Peixe, associou-se à Ponzoni, 
Brandalise \& Cia, formando a Sociedade de Banha Catarinense Ltda. Na nova fábrica de produtos suínos, os italianos ficaram encarregados da comercialização das matérias-primas e dos produtos e os alemães continuaram como responsáveis pela área de produção.

Além dos armazéns de secos e molhados com venda no atacado e varejo e da atuação no abate e industrialização de suínos, na década de 1930 a Ponzoni, Brandalise \& Cia atuava na compra e venda de suínos, adquirindo-os dos criadores locais e vendendo-os em São Paulo. Buscando diversificar suas atividades, em 1940 a firma fundou a Sociedade de Vinhos Catarinense Ltda.

\subsection{Expansão dos negócios nas décadas de 1940 e 1950}

Quando a Ponzoni, Brandalise \& Cia assumiu o abatedouro de suínos e fábrica de banha, contava com 35 funcionários encarregados de todas as tarefas, tanto de abate como de preparação dos subprodutos. "Davam conta do abate de 15 a 25 suínos por dia, além de vários outros animais como coelhos, ovelhas, cabritos, patos, marrecos e perus; cuidavam do processamento da banha e das carnes de todos os animais" (Tassara e Scapin, 1996: 44).

$\mathrm{Na}$ época, a principal criação era do "porco tipo banha", atividade associada ao cultivo de diferentes gêneros agrícolas (trigo, milho, centeio, cevada, uva, feijão, batata...), que serviam de alimento na engorda dos animais. A criação era feita pelos pequenos proprietários de origem alemã e italiana. Pequenos abatedouros do Sul tinham de vender seus produtos na região e/ ou transportá-los para São Paulo e Rio de Janeiro, onde concorriam com marcas conhecidas de empresas proprietárias de grandes frigoríficos que se instalaram no Rio Grande do Sul e em São Paulo no início do século XX, tais como Armour, Swift e Wilson.

Em 1941, a firma Ponzoni, Brandalise \& Cia tinha uma gama diversificada de produtos derivados das diversas atividades industriais; entretanto, faltava-lhe uma marca que identificasse as mercadorias. Após diversas tentativas, definiu-se o nome Perdigão, originário das perdizes e perdigões, caçados nos campos da região, e em homenagem à vila de Perdizes (atual Videira). ${ }^{7}$ "Em 1942, durante a $1^{\text {a }}$ Festa da Uva de Santa Catarina, realizada em Perdizes, os produtos da 'fábrica de banha' foram expostos já com a marca Perdigão: banha, presunto, salame, lingüiça, salsicha, carnes defumadas e carnes salgadas" (Tassara e Scapin, 1996: 50). 
Em 1943, buscando diversificar suas atividades, a Ponzoni, Brandalise \& Cia. adquiriu a Sociedade Curtume Catarinense, englobando outra parte do ciclo produtivo com o processamento industrial de couros de seu abatedouro e de terceiros.

Em 1946, a agora denominada Ponzoni Brandalise S.A. Comércio e Indústria, construiu próximo ao abatedouro de Videira um segundo moinho de trigo com capacidade de produção de seis toneladas diárias de farinha. Dez anos depois, essa capacidade elevou-se para 25 toneladas/dia.

Em 1947, a Ponzoni Brandalise fez seu primeiro investimento no setor madeireiro, adquirindo uma serraria em Tangará. Aumentando sua participação no setor, logo depois instalou outra serraria nesse município e uma terceira em Catanduvas.

No início da colonização da região oeste de Santa Catarina e nas décadas seguintes, galinhas e frangos, patos, marrecos e perus costumavam ser criados soltos nos pátios e quintais de forma doméstica, sendo consumidos apenas aos domingos ou em ocasiões especiais. Em 1954, a empresa decidiu aprimorar a produção dessa matéria-prima e dos suínos abatidos em seu frigorífico. Para tanto, fundou a Granja Santa Gema, que em seguida começou um programa de melhoramento genético em suinocultura, trabalhando com as raças Duroc Jersey (EUA), Landrace (Suécia), Berchshire Wessex, Sadblack e Hampshire (Inglaterra).

Em 1955, para colaborar na melhoria da qualidade dos plantéis, a Ponzoni Brandalise construiu próximo ao frigorífico uma fábrica de rações balanceadas para atender aos produtores que the forneciam os animais.

A Ponzoni Brandalise S.A. havia se transformado em um complexo de empresas interligadas. Atuava com granja, abatedouro, fábrica de banha e frigorífico, curtume, moinhos, fábrica de rações, madeireira, fábrica de caixas, entrepostos, depósitos, postos de venda, lojas e filias comerciais em várias cidades na região produtora, São Paulo, Bauru, Santos e Rio de Janeiro.

Nessa etapa da história da empresa observa-se a primeira diversificação importante nas atividades. De um lado, a concentração no "foco" da firma, que estava voltado para a moagem de milho-trigo, para a obtenção de farinhas, e para o abate de aves e suínos, obtendo a banha (utilizada na cozinha como se utiliza atualmente o óleo vegetal) e carnes e derivados. De outro lado, conseqüência da expansão, o aumento de atividades de suporte e/ou novos setores de atuação. 
Para acompanhar as diferentes atividades e os aumentos de produção, no final dos anos 1950, a Perdigão contava com 400 empregados. Tinha em seu patrimônio 160 casas para os operários; uma fazenda em Cruzeiro (PR), com três mil pés de café e rebanho bovino; uma fazenda em Campos Novos (SC), para a criação e engorda de bovinos; maquinário para beneficiamento e classificação de feijão, descascador de arroz e maquinário para refino de açúcar cristal. Além disso, mantinha participação societária em diversas outras empresas localizadas no oeste catarinense (Tassara e Scapin, 1996).

\subsection{Décadas de 1960 e 1970: crescimento industrial e diversificação de empresas e produtos}

"Em 1960 o abate de frangos na Perdigão se resumia ao trabalho de duas mulheres que, artesanal e manualmente, processavam cerca de 120 aves por semana" (Tassara e Scapin, 1996: 65). No mesmo ano, a empresa enviou um técnico aos EUA para participar de um curso de especialização em avicultura. Fruto dos avanços introduzidos a partir dessa viagem, em 1962, teve início, ainda experimentalmente, o abate de cerca de 500 frangos por dia. As aves abatidas eram resfriadas, transportadas e comercializadas em São Paulo. Em pouco mais de cinco anos a empresa, que comprou uma pequena máquina depenadeira semi-automática, atingiu a meta de 1.500 frangos abatidos por dia. ${ }^{8}$

Nas épocas de final de ano, além dos suínos, frangos e bovinos (cerca de oito a 10 por dia, destinados à fabricação de salames e à venda no próprio açougue), abatiam-se coelhos, ovelhas, cabritos, patos e perus, também comercializados em São Paulo.

Em 1955, para solucionar o problema do transporte e distribuir os produtos da empresa, foi constituída a Ponzoni Brandalise - Comércio, Indústria e Transportes. Dois anos depois de sua constituição, o Expresso Perdigão, como ficou conhecido, passou a contar com 20 caminhões. Como as estradas eram precárias e não havia refrigeração nos caminhões, a Perdigão resolveu transportar seus produtos perecíveis em avião entre Videira e São Paulo. Foi assim que, em 1957, adquiriu dois aviões Douglas DC-3, com capacidade para transportar três toneladas de carga por viagem.

Apesar da rapidez dos aviões, o Expresso Perdigão continuou a existir e crescer. Com a modernização das estradas de rodagem, patrocinada pelo 
governo Kubitschek, e com o advento das câmaras frigoríficas, o transporte terrestre por caminhões passou a ser econômica e tecnicamente mais interessante do que a manutenção dos velhos aviões, que foram desativados e vendidos.

Entre 1956 e 1958, houve uma reestruturação administrativa, quando a empresa passou a se chamar Perdigão S.A. Comércio e Indústria. Foi também nessa ocasião que o controle acionário e a direção passaram para a família Brandalise. ${ }^{9}$

No início dos anos 1960, os principais produtos fabricados eram a banha e os cortes de carne. Entre estes destacavam-se o lombo, o filé e a costela, que eram resfriados e transportados em avião e, em seguida, em caminhão, para serem comercializados em São Paulo. Também produziam-se embutidos, salgados e defumados (salames, copas, miúdos e presunto tipo Parma), podendo ser transportados por terra, sem problemas. Havia ainda os produtos frescais (lingüiças tipo toscana e calabresa, presunto cozido, salsichas, queijo de porco, patês e mortalelas), destinados à venda local.

A tecnologia e os métodos de industrialização eram totalmente manuais. Os funcionários que trabalhavam no frigorífico contavam apenas com o auxílio de um moedor de carnes e uma misturadeira; as embutideiras para as lingüiças eram de ar comprimido ou manuais.

Nessa fase da empresa, destaque para o aprofundamento em direção ao core business, quando novos produtos em derivados de carnes foram incluídos. Por outro lado, as atividades-suporte, tais como serviços de transporte, vendas e fornecimento de embalagens, também aumentaram, diversificando para setores que prejudicariam, mais tarde, a eficiência-eficácia da firma.

No final da década de 1960, com o aumento da produção, a Perdigão investiu na montagem de suas próprias filiais de vendas. Entre 1968-1969, instalou filiais comerciais e importadoras nos principais centros do País (São Paulo, Bauru, Santos, Rio de Janeiro), visando a distribuir os produtos provenientes do Sul.

Somando-se os ramos de atividade da metade dos anos 1970, o grupo Perdigão possuía 1.400 funcionários. Em 1974, Saul Brandalise assumiu a posição de presidente-executivo, sendo auxiliado por parentes próximos — André David, seu irmão, Flávio e Saul Junior, seus filhos —, sócios e ami- 
gos, como Achyles Emilio Ponzoni, Luis Gabriel e Angelo Leoni, antigos colaboradores. Apesar de alguns diretores serem de fora da família, caracterizava-se na empresa a "sociedade entre irmãos" (Gersick et al., 1998), quando os filhos do fundador assumiram a direção.

Até 1976, a Perdigão Alimentos ficou sob o comando de Flávio Brandalise que antes e por mais de 10 anos, ocupara o cargo de diretor-tesoureiro. Em 1978, Flávio deixou a Perdigão Alimentos nas mãos de seu irmão, Saul Brandalise Junior, para assumir a vice-presidência. Pouco a pouco, a exemplo do que havia ocorrido em sua própria história, Saul Brandalise foi introduzindo os filhos na administração das empresas que ele, seus irmãos e a família Ponzoni haviam construído. Passava-se, no final da década de 1970, para a transição em direção ao "consórcio de primos" (Gersick et al., 1998), introduzindo-se a terceira geração na administração.

Desenvolvendo e aperfeiçoando o sistema de parceria na criação de frangos com os pequenos agricultores da região, foi possível aumentar a produção e melhorar a produtividade. Esse sistema de produção permitiu, a partir de 1975, a construção, em Videira, do primeiro abatedouro da Perdigão exclusivo para aves.

Ainda em 1975, a Perdigão, junto com a Sadia e a Seara, fez um pool para dar início às exportações nacionais de frango, constituindo a UNEF - União de Exportadores de Frangos, que deu origem à atual ABEF - Associação Brasileira de Produtores e Exportadores de Frangos. O primeiro lote, enviado pela Perdigão à Arábia Saudita, foi embarcado no navio Aconcágua. Desse momento em diante, as exportações continuaram crescendo e, a partir de 1984, as mesmas empresas do Sul que iniciaram suas vendas no exterior, assim como as demais que se voltaram para o mercado externo, capacitaram-se para exportar também frangos em partes. Resultado desse movimento de expansão, as exportações de carne de frango passaram de 4 mil toneladas, em 1975, para 2,469 milhões de toneladas, em 2004. O valor das exportações do Brasil passou de US\$ 3,3 milhões para US\$ 2,6 bilhões nas respectivas datas. Ao longo desse período, a Perdigão se manteve como a segunda maior exportadora nacional.

Nessa etapa do desenvolvimento da firma aconteceu um aprofundamento do core business, destacando-se duas áreas: abate de animais e industrialização de carnes e derivados, oferecendo uma gama maior de produtos. 
Como resultado da expansão e crescimento, novos setores foram incorporados, setores esses que, mais tarde, teriam conseqüências sérias de administração, devido à diversificação nos ramos de atividade.

\subsection{Perdigão: de Videira para outras regiões do Estado e do País}

Desde sua fundação até meados da década de 1970, a Perdigão multiplicou suas atividades industriais e comerciais quase só no município de Videira, sendo a principal responsável pelo desenvolvimento e benfeitorias do lugar, na cidade e no campo.

A partir da metade dos anos 1970, essa política mudou, com a compra do Frigorífico Unifrico S.A., de Salto Veloso, município localizado no Alto Vale do Rio do Peixe, no meio-oeste catarinense.

Para dar continuidade ao processo de expansão, em 1980 a Perdigão S.A. abriu seu capital, colocando ações à venda na Bolsa de Valores de São Paulo, o que lhe permitiu gerar parte dos recursos necessários ao crescimento.

Acompanhando a expansão territorial veio uma diversificação na gama de produtos. Em 1979, a Perdigão enviou dois técnicos, Mário Ricciardi e Edésio Jacó Brandalise, aos Estados Unidos em busca de duas linhagens de avós: ${ }^{10}$ uma de frangos de corte e uma de perus. Depois de conhecer os processos de produção norte-americanos, optaram pelo Chester, uma ave híbrida, constituída de carnes nobres, com cerca de $70 \%$ do peso localizado no peito e nas coxas. Lançado em 1982, esse novo produto teve uma rápida penetração no mercado, graças às suas qualidades e ao investimento em propaganda.

Diversificando sua linha de produção avícola, a Perdigão iniciou, em 1989, o desenvolvimento da criação de aves exóticas, tais como a codorna e o chukar (ave aparentada da perdiz, originária do norte do Paquistão). Ampliando essa linha, incluiu o faisão, cuja criação foi terceirizada, sendo realizada em Rio Claro (SP).

A criação de codornas e de chukar é feita a partir de matrizes selecionadas desenvolvidas pela empresa francesa Faisanderies du Grand Clos. No caso das codornas, a criação passou a ser realizada pela própria empresa, e o chukar é criado por parceiros em sistema de integração. "Em poucos anos, a unidade de Videira passou a abater cerca de 13 mil chukar e 27 mil codornas por semana" (Tassara e Scapin, 1996: 100). 
A década de 1980 foi de diversificação territorial e de ramos de negócios. Em 1980, a Perdigão passou a controlar a Agropecuária Confiança, a Comércio e Indústria Saulle Pagnoncelli e a Reflora - Empresa de Reflorestamento, localizadas na região de Herval d'Oeste, além das Indústrias Reunidas Ouro, em Capinzal. Em 1981, adquiriu a Nodarisa Empreendimentos Florestais de Curitiba, para administrar as fazendas de reflorestamento e de produção de maçãs em Fraiburgo (SC) e Guarapuava (PR).

Em Santa Catarina aumentou as aquisições em 1984, comprando a Suely Avícola, com instalações nas regiões de Orleans, Içara, Jaguaruna e Taió, com granjas de matrizes, incubatórios e fábricas de rações. No mesmo ano foi adquirido o Frigorífico Canta Galo, de Criciúma.

Em 1985, a Perdigão começou sua expansão no Rio Grande do Sul ao comprar a Cooperativa Tritícola Taperense, filiais de Gaurama, Severiano de Almeida e Aratiba, cuja atividade principal era a compra e comercialização de grãos. No mesmo ano, comprou o Grupo Borella, em Marau (RS), voltado para o abate de aves e a produção de óleos vegetais.

Em 1986, investiu em um novo segmento de carnes, entrando para o abate e industrialização de bovinos. Para isso comprou o Frigorífico Planalto, em Lages (SC), que, após ser reformado e ampliado, passou a abater cerca de 500 bovinos por dia.

Em 1988, no Rio Grande do Sul, foram incorporadas a Sulina Alimentos, a Ideal Avícola e a Granja Ideal, todas sediadas no município de Serafina Corrêa, voltadas para o abate e a industrialização de frangos. No ano seguinte, a Perdigão investiu na constituição de uma fábrica de rações, sediada em Francisco Beltrão (PR).

Em 1989, distanciou-se ainda mais de seu local de origem ao comprar os ativos da Swift, frigorífico instalado em Santo André, na grande São Paulo. Com essa aquisição, a empresa passou a atuar na área de alimentos vegetais e enlatados (ervilhas, milho verde, purê e extrato de tomates, maioneses etc.), além de manter os derivados de carne enlatados que a Swift produzia (salsichas, almôndegas, feijoada etc.) que passaram a ser comercializados com as marcas Perdigão e “Toque de Sabor”. Ainda em São Paulo, no mesmo ano, comprou o Frigorífico Mococa, que incluía incubatórios, granjas, abatedouro de frangos e fábrica de rações (tabela 1). 


\section{Tabela 1: Perdigão - ano de fundação, distribuição geográfica e atividades de suas principais empresas, 1934-2005}

\begin{tabular}{|c|c|c|c|}
\hline Ano & Cidade-Estado & Empresa & Atividade \\
\hline 1934 & Videira (SC) & Ponzoni, Brandalize e Cia. & Comércio de "secos e molhados" \\
\hline 1937 & Luzerna (SC) & Ponzoni, Bonato e Cia. & Comércio em geral \\
\hline 1939 & Videira (SC) & Sociedade de Banha Catarinense & Fábrica de produtos suínos \\
\hline 1940 & Videira (SC) & Sociedade de Vinhos Catarinense & Vinho e outros derivados de uva \\
\hline 1943 & Videira (SC) & Sociedade Curtume Catarinense & Industrialização de couros e peles \\
\hline 1947 & Tangará (SC) & Ponzoni, Brandalise e Cia. & Serraria e fábrica de caixas \\
\hline 1955 & Videira (SC) & Expresso Perdigão & Transporte de mercadorias \\
\hline 1955 & Videira (SC) & Ponzoni, Brandalise e Cia. & Fábrica de rações \\
\hline 1957 & Videira (SC) & Transporte Aéreo & Transporte de produtos perecíveis \\
\hline 1962 & Videira (SC) & Perdigão S.A. & Abate e industrialização de frangos \\
\hline 1965 & Videira (SC) & Perdigão Serviços Ltda. & Gráfica e serviços em geral \\
\hline 1968 & São Paulo (...) & Filiais comerciais & Comercialização dos produtos Perdigão \\
\hline 1971 & Joaçaba (SC) & Empório de Couros S.A. & Industrialização de couros e peles \\
\hline 1972 & Videira (SC) & Soc. Esportiva e Recreativa Perdigão & Lazer para os funcionários \\
\hline 1973 & Videira (SC) & Supermercado & Perdigão Vendas a varejo \\
\hline 1973 & Videira (SC) & San Raphael Palace Hotel & Serviços de hotelaria \\
\hline 1974 & Videira (SC) & Perdigão Alimentos S.A. & Produção de ração, farelo e óleo de soja \\
\hline 1974 & Marau (RS) & Perdigão Alimentos S.A. & Produção de ração, farelo e óleo de soja \\
\hline 1975 & Videira (SC) & Abatedouro exclusivo para aves & Abate e industrialização de aves \\
\hline 1977 & Salto Veloso (SC) & Frigorífico Unifrico S.A. & Abate e industrialização de suínos e aves \\
\hline 1979 & Medianeira (SC) & Armazéns Medianeira & Atividades de armazenagem \\
\hline 1979 & Catanduvas (SC) & Fábrica de rações & Produção de rações para aves e suínos \\
\hline 1979 & Fraiburgo (SC) & Nodarisa Empreend. Florestais & Cultivo de maçãs \\
\hline 1980 & Videira (SC) & Perdigão S.A. Comércio e Indústria & Ações na Bolsa de Valores \\
\hline 1980 & Herval d'Oeste (SC) & Agropecuária Confiança & Atividades agropecuárias \\
\hline 1980 & Capinzal (SC) & Indústrias Reunidas Ouro & Abate e industrialização de aves e suínos \\
\hline 1982 & Videira (SC) & Perdigão S.A. Ind. e Com. & Lançamento do Chester \\
\hline 1984 & Orleans (SC) & Suely Avícola S.A. & Granjas de matrizes, rações e incubatórios \\
\hline 1984 & Criciúma (SC) & Frigorífico Canta Galo & Abate de aves \\
\hline 1985 & Aratiba (RS) & Coop. Tritícola Taperense & Compra de cereais \\
\hline 1985 & Marau (RS) & Grupo Borella & Abate e industrialização de suínos e aves \\
\hline 1986 & Lages (SC) & Frigorífico Planalto & Abate e processamento bovino \\
\hline 1988 & Serafina Corrêa (RS) & Sulina Alimentos & Abate de aves \\
\hline 1989 & Francisco Beltrão (PR) & Perdigão S.A. & Abate e industrialização de aves \\
\hline 1989 & Santo André (SP) & Swift Alimentos & Vegetais e carnes enlatadas \\
\hline 1989 & Mococa (SP) & Frigorífico Mococa S.A. & Incubatório e abate de frangos \\
\hline 1989 & Capinzal (SC) & Joint Venture com Mitsubishi & Exportação de frango para o Japão \\
\hline 1995 & Marau (RS) & Perdigão S.A. & Fábrica de industrializados de suínos \\
\hline 1998 & Rio Verde (GO) & Complexo Agroindustrial & Abatedouro e fábrica de embutidos \\
\hline 2000 & Carambeí (PR) & Frigorífico Batávia & Abate e industrialização de perus \\
\hline
\end{tabular}

Fonte: Elaboração própria a partir do material da empresa e pesquisa de campo. 
No mesmo ano, a empresa fez uma parceria com a Mitsubishi Corporation do Japão (maior empresa importadora de carnes daquele país), através da qual conseguiu recursos e acesso às tecnologias necessárias para a produção de cortes especiais destinados ao mercado japonês. Com isso, pôde modernizar a unidade industrial de Capinzal (SC), adequando suas linhas de produção e instalando salas de corte capazes de atender às exigências específicas dos consumidores japoneses.

\subsection{Crise administrativa e mudanças no comando da direção da Perdigão}

Com o final da década de 1980, terminou também o primeiro ciclo expansionista do grupo. Em 10 anos, a Perdigão ganhara diversas colocações entre as 500 maiores empresas brasileiras, passando do $211^{\circ}$ para o $52^{\circ}$ lugar. Seu faturamento passara para a ordem de US\$ 510 milhões por ano, e contava com um quadro de funcionários de 16 mil pessoas.

Junto com as aquisições das décadas de 1970 e 1980, a Perdigão acumulou uma série de problemas. Transformou-se em um gigante de difícil administração, com muitas dívidas assumidas para gerar o capital necessário às novas aquisições e com graves dificuldades administrativas.

Um complexo empresarial híbrido, desvirtuado de sua verdadeira vocação como empresa do ramo agroindustrial e frigorífico, disperso e com empresas atuando em atividades muito diferentes e sediadas em pontos tão distantes entre si, como o Mato Grosso e o Rio Grande do Sul. (Tassara e Scapin, 1996: 109)

Com o objetivo de sanar tais dificuldades, em 1985 a direção da Perdigão tomou as primeiras iniciativas no sentido de promover a profissionalização da gestão. Para tanto, Saul Brandalise, então presidente do grupo, contratou Ivan Bonato, seu genro, recém-saído da Secretaria da Fazenda do Estado de Santa Catarina, que levou outros profissionais especializados em administração de negócios. Logo em seguida tais projetos foram abandonados, quando Ivan Bonato se desligou da empresa para dedicar-se à política.

Em 1987, Flávio Brandalise assumiu a presidência, ficando no lugar de seu pai, que continuou presidindo o conselho administrativo. Saul Brandalise Junior tornou-se responsável pela direção da Perdigão Agropecuária S.A., que concentrava toda a área de produção, onde ficou até 1989. Nesse mesmo ano ocorreu nova reordenação administrativa, quando Saul Bran- 
dalise Junior assumiu o cargo de diretor vice-presidente e seu cunhado, Ivan Bonato, retornando à Perdigão, ocupou a vice-presidência executiva, de onde se retirou alguns anos depois, para cuidar dos negócios de sua família.

A partir de 1990, os controladores, formados pela família Brandalise, pressionados por seus acionistas minoritários, iniciaram a tomada das medidas necessárias para a sua reorganização, tendo em vista um programa de enxugamento e de saneamento dos negócios. Esse processo incluiu cortes de despesas administrativas, principalmente com pessoal e com burocracia; reestruturação de suas atividades industriais e comerciais; desmobilização com a venda de ativos não operacionais, tais como imóveis urbanos, terrenos, fazendas de reflorestamento, plantações de frutas, até unidades produtivas que se distanciavam de sua atividade principal.

Porém, os resultados dessa reorganização ficaram aquém dos exigidos pelo tamanho da crise e insuficientes para superar as dificuldades. As dívidas assumidas nos anos anteriores, junto aos bancos e fornecedores, "continuavam a crescer em virtude dos juros altos e da perda de confiança do mercado financeiro nos gestores da empresa" (Tassara e Scapin, 1996: 110).

Em 1992, ano do falecimento de Saul Brandalise, submetidos à pressão dos credores e acionistas minoritários que sustentavam que a melhor alternativa era a profissionalização da gestão, os controladores e acionistas majoritários, compostos pela terceira geração da família Brandalise, perderam a presidência do grupo.

Nessa segunda tentativa de profissionalização foi contratado um profissional que, a princípio, assumiu a diretoria financeira e em seguida foi promovido à presidência. A situação dos controladores se complicou, e para os que acreditavam na continuidade da empresa como empreendimento rentável, a única solução parecia ser a transferência de seu controle acionário.

Em março de 1993, um novo acordo de acionistas colocou outro presidente no conselho administrativo, Eggon João da Silva, fundador e presidente da Weg Motores, desde 1986 detentora de participação acionária na Perdigão e, naquele momento, representante dos acionistas minoritários. Em outubro do mesmo ano, Eggon assumiu também a presidência executiva da Perdigão, iniciando o processo de preparação da transferência do controle acionário. 


\section{PERDIGÃO REENCONTRA SUA ROTA EM NOVAS MÃOS}

Apesar da gravidade da situação, a Perdigão era um empreendimento viável, com possibilidades de se reestruturar e voltar a crescer. Tratava-se de uma empresa com base industrial, composta de 10 unidades de processamento e oito fábricas de ração, dispondo de tecnologia, tanto no que diz respeito ao seu equipamento industrial como em relação à sua área de seleção genética, pesquisa e desenvolvimento de matrizes para reprodução, tendo acumulado experiência na implantação de um parque criatório, próprio e de terceiros, com mais de 10 mil parceiros integrados. Contava com uma rede de 28 armazéns distribuidores espalhados por todo o País, entre filiais próprias e terceirizadas, com uma carteira de clientes, e com estrutura internacional para dar suporte às exportações para mais de 40 países.

Acima de tudo, a Perdigão era dona de uma marca consagrada, com uma extensa linha de produtos. No segmento aves, produzia e comercializava frango inteiro ou em partes; pré-preparados, empanados, hambúrgueres, aves especiais e seus derivados. No segmento de carnes suínas, trabalhava com cortes de carne congelada, salgada ou defumada, embutidos e presuntos. Com as carnes bovinas, produzia hambúrgueres e almôndegas. Para completar a gama de produtos comercializados com a marca Perdigão, estavam o óleo de soja e as rações balanceadas.

O processo de transferência do controle acionário só ocorreu em setembro de 1994, com a venda das ações da família Brandalise e o seu afastamento definitivo da Perdigão. Em janeiro daquele ano, foi contratado o Banco de Investimentos Garantia para assessorar a Videira Empreendimentos Ltda., holding da família Brandalise. Após análise e rejeição de algumas propostas, a Perdigão negociou com o Banco Icatu, a partir de uma proposta feita por um pool formado por fundos de pensão. Assim, “em um negócio de US\$ 150 milhões, correspondentes a 70,6\% do capital votante da empresa, a família Brandalise encerrou sua participação na Perdigão, saldando suas dívidas com a mesma e com os demais acionistas" (Tassara e Scapin, 1996: 110).

Logo que assumiu o controle da Perdigão, esse pool de fundos de pensão, ${ }^{11}$ juntamente com o Bradesco, a Weg Motores e os representantes dos demais acionistas minoritários, elegeu um novo conselho de administração e um conselho fiscal, alterou os estatutos e contratou uma empresa internacio- 
nal de consultoria para selecionar um executivo que passaria a conduzir seus negócios. Passava-se de uma administração familiar para uma gestão profissional. A partir dessa decisão, a Perdigão deixou de ser uma "empresa familiar" para tornar-se uma "empresa moderna", na concepção chandleriana.

Terminada a fase de transição, em janeiro de 1995 tomou posse como diretor-presidente o engenheiro Nildemar Secches. A partir daí iniciou-se a reorganização da empresa, em um processo de modernização administrativa, racionalização e enxugamento de gastos. A primeira decisão foi concentrar forças na atividade principal do grupo, ou seja, produção, industrialização e comercialização de aves e suínos. As operações de soja, transporte, recursos energéticos e processamento de carne bovina passaram a ser consideradas atividades de suporte.

Tassara e Scapin (1996) descrevem esse processo dizendo que, após uma exaustiva análise de toda a estrutura vigente, a Perdigão foi reestruturada. Em primeiro lugar, a corporação passou a ser integrada por apenas quatro empresas: Perdigão S.A., Perdigão Agroindustrial, Perdigão Overseas (voltada para operações de financiamento no exterior) e Avícola Rio Claro.

Alguns empreendimentos e empresas controlados antes pela Perdigão foram vendidos; outros, desativados, extintos ou incorporados a uma das quatro novas empresas. Muitos serviços foram terceirizados e outros, ampliados. O objetivo da nova administração, além de sanear financeiramente o grupo e de atuar com o máximo de transparência em face dos acionistas, era a mudança da cultura empresarial.

A partir de 1995, a primeira fase de seu Projeto de Otimização das Fábricas já instaladas previa a expansão da produção em 50\%, para recuperar a tradicional porcentagem de vendas no mercado brasileiro. ${ }^{12}$ Para tanto, a empresa decidiu construir uma nova fábrica de industrializados de suínos em Marau (RS), além de investir na modernização e aumento de capacidade instalada das demais unidades industriais nos outros Estados.

A segunda etapa do crescimento previa a construção de duas novas unidades industriais com seus respectivos complexos agropecuários, objetivando alcançar, até o ano 2003, o abate de cerca de 1,3 milhão de aves e 10 mil suínos por dia.

A tabela 2 aponta as principais transformações pelas quais a empresa passou após sua profissionalização, tanto em relação ao faturamento bruto 
Tabela 2: Perdigão - evolução dos principais indicadores, 1994-2004

\begin{tabular}{lcccccccc}
\hline Itens & 1994 & 1996 & 1998 & 2000 & 2001 & 2002 & 2003 & 2004 \\
\hline $\begin{array}{l}\text { Faturamento bruto* } \\
\text { interno }\end{array}$ & 354,0 & 773,0 & $1.108,0$ & $1.554,0$ & $1.754,0$ & $2.135,7$ & $2.533,1$ & $1.984,0$ \\
\hline $\begin{array}{l}\text { Faturamento bruto* } \\
\text { externo }\end{array}$ & 116,0 & 244,0 & 307,0 & 512,0 & $1.035,0$ & $1.205,9$ & $1.837,8$ & $2.006,0$ \\
\hline $\begin{array}{l}\text { Faturamento bruto* } \\
\text { total }\end{array}$ & 470,0 & $1.017,0$ & $1.415,0$ & $2.066,0$ & $2.789,0$ & $3.341,7$ & $4.370,9$ & $3.990,0$ \\
\hline \begin{tabular}{l} 
Lucro líquido* \\
\hline
\end{tabular} & 12,2 & 9,8 & 60,4 & 45,0 & 168,0 & 8,2 & 123,5 & 211,0 \\
\hline $\begin{array}{l}\text { Funcionários } \\
\text { *Em milhões de reais. }\end{array}$ \\
$\begin{array}{l}\text { Fonte: Elaboração própria a partir dos Relatórios Anuais e site da empresa. } \\
14.313\end{array}$ & 15.192 & 19.291 & 22.377 & 24.163 & 27.951 & 30.943 \\
\hline
\end{tabular}

Tabela 3: Evolução da capacidade instalada de abate e/ou industrialização, 1994-2004

\begin{tabular}{lcccc}
\hline Capacidade & 1994 & 2000 & 2003 & 2004* $^{*}$ \\
\hline $\begin{array}{l}\text { Abate de aves } \\
\text { (mil cab./semana) }\end{array}$ & 2.715 & 6.540 & 9.000 & 9.550 \\
\hline $\begin{array}{l}\text { Abate de suínos } \\
\text { (mil cab./semana) }\end{array}$ & 22 & 44 & 64 & 68 \\
\hline $\begin{array}{l}\text { Frigorificados aves } \\
\text { (mil ton./semana) }\end{array}$ & 162 & 409 & 570 & 621 \\
\hline $\begin{array}{l}\text { Frigorificados suínos } \\
\text { (mil ton./semana) }\end{array}$ & 159 & 306 & 450 & 465 \\
\hline $\begin{array}{l}\text { Total frigorificados } \\
\text { (mil ton./semana) }\end{array}$ & 321 & 715 & 1.020 & 1.086 \\
\hline Total & 3.379 & 8.014 & 11.104 & 11.790 \\
\hline * Previsão. & & &
\end{tabular}

Fonte: Elaboração própria a partir do Relatório Anual da Perdigão, 2003: 17.

quanto ao número de funcionários, que passou de 12 para mais de 30 mil. Destaque para a internacionalização, com forte impulso na virada do milênio. ${ }^{13}$

Para chegar a esses resultados, a Perdigão investiu no aumento de sua capacidade instalada, tanto no abate de aves e suínos quanto na fabricação de embutidos e industrializados de carnes, chegando a um aumento de $310,3 \%$ na última década.

Todos esses investimentos refletiram-se no faturamento bruto da empresa. O gráfico 1 demonstra essa evolução no mercado interno e externo. Nesse caso, o aumento foi de $848,9 \%$ no mesmo período.

Um dos segredos empresariais no agronegócio é a capacidade das empresas de produzirem mercadorias com maior valor agregado, aumentando, 
Gráfico 1: Faturamento bruto da Perdigão, 1994 a set./2004

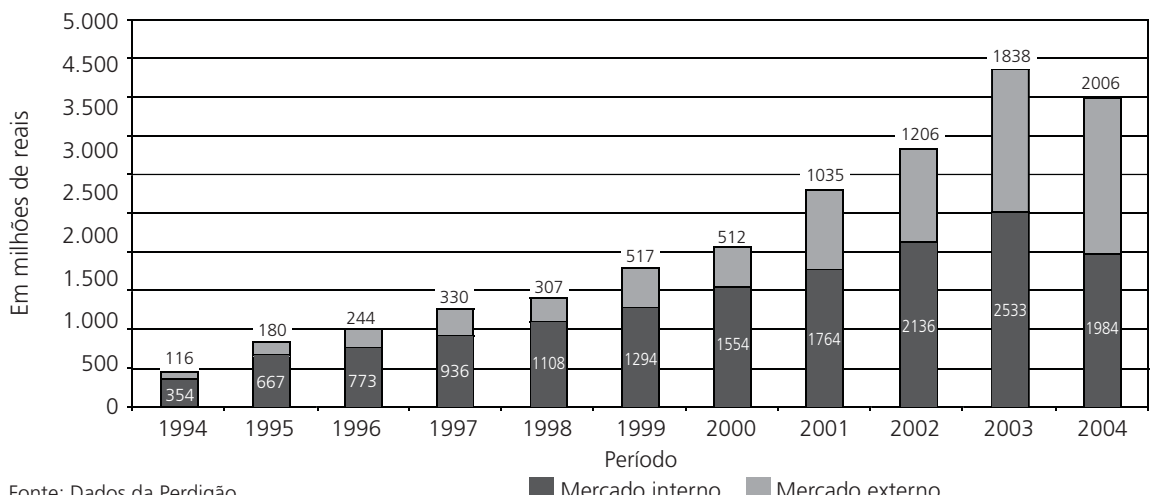

Fonte: Dados da Perdigão.

Mercado interno Mercado externo

Gráfico 2: Perdigão - produção de frigorificados de aves e suínos, 1994 a set./2004 (em mil toneladas)

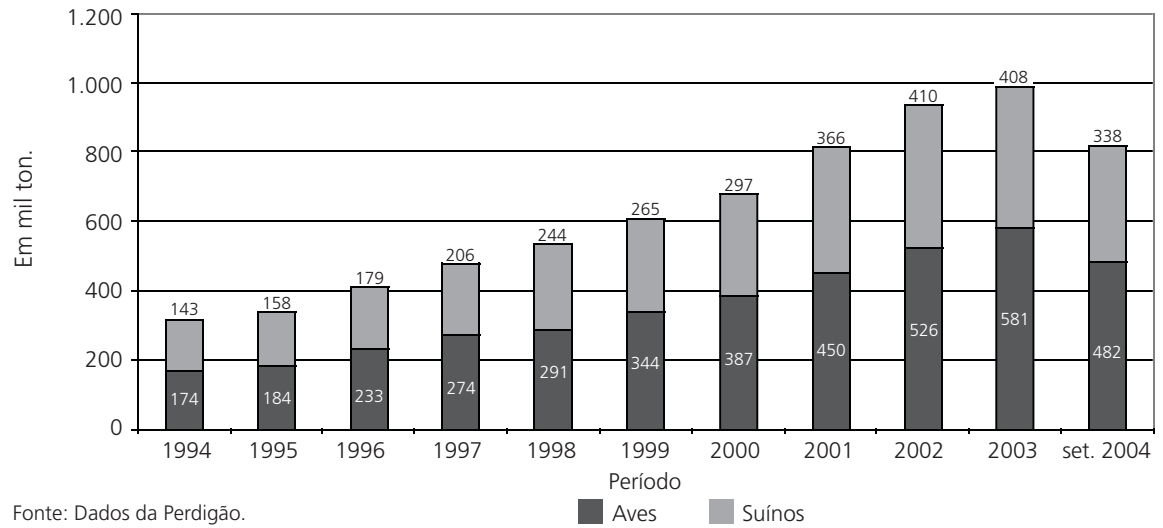

assim, sua lucratividade. Tratando-se da produção de frigorificados, derivados de aves e suínos, a Perdigão teve um crescimento de $258,6 \%$ na última década.

Para a Perdigão e suas concorrentes, a produção de aves e suínos baseiase no consumo de rações, cuja matéria-prima fundamental é o milho e a soja. O gráfico 3 ajuda a entender a importância da produção desses grãos para garantir a continuidade do crescimento desse tipo de produção. O consumo desses produtos pela empresa aumentou em 352,9\% para atender a seus produtores integrados. 
Gráfico 3: Perdigão - consumo de grãos, 1994 a 2003 (em mil toneladas)

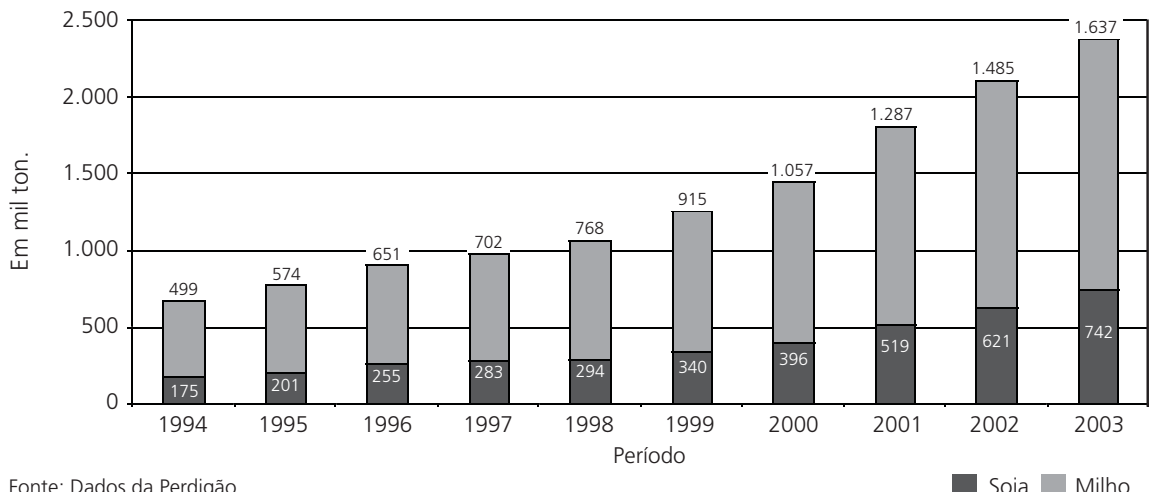

Fonte: Dados da Perdigão.

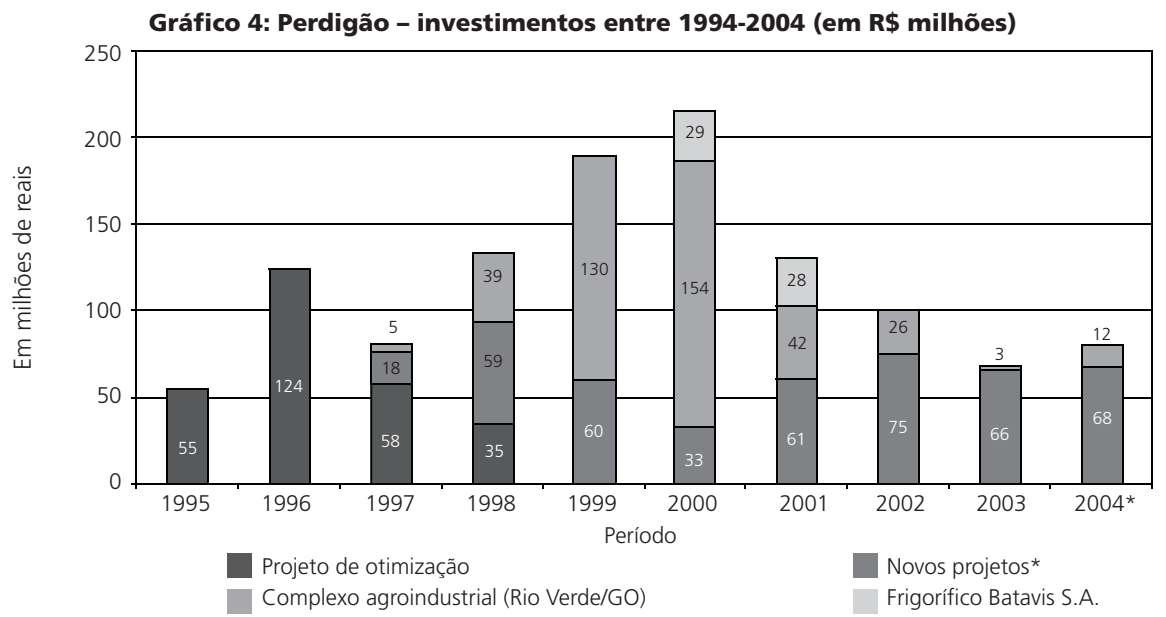

Fonte: Perdigão. Relatório Anual, 2004.

Os resultados destacados acima só foram conseguidos graças a uma política de constantes investimentos, tanto nos projetos de otimização das fábricas e demais parques industriais quanto em novos projetos. Com um investimento médio de R\$ 118 milhões (gráfico 4), a Perdigão capacitou-se para ser uma grande empresa do setor alimentar, garantindo seu espaço tanto no mercado interno quanto nas exportações.

Após quatro anos de gestão profissionalizada, foi tomada uma decisão estratégica que mudou os rumos da empresa, passando esta de uma agroin- 
Gráfico 5: Perdigão - market-share dos produtos (em percentual)

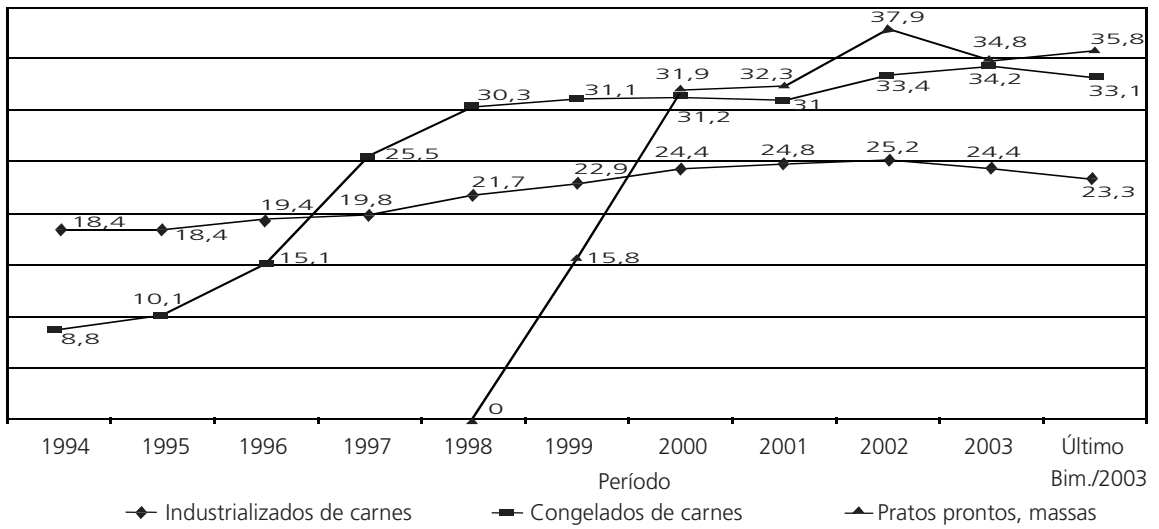

Fonte: Dados da Perdigão.

dústria para uma produtora de alimentos congelados e industrializados de carnes, pratos prontos e massas. Em apenas dois anos de atuação nesse setor, os pratos prontos e massas passaram a mais de um terço do market-share da Perdigão no mercado nacional. A inovação e o lançamento de novos produtos são indispensáveis para manter essa performance. Em 2003, foram lançados 31 novos produtos, 18 com a marca Perdigão e 13 com a marca Batavo (Perdigão, Relatório anual, 2003: 3).

As transformações pelas quais a Perdigão passou na passagem de "empresa familiar" para "moderna" se refletiram na volta a seu foco, quando o core business passou de agroindústria para empresa de alimentos. Nesse aspecto houve diversificação e aprofundamento no leque de opções aos consumidores. Por outro lado, as atividades-suporte, como transportes, vendas, fornecimento de matéria-prima, foram sublocadas ou terceirizadas, aumentando a eficiência e a competitividade da firma.

Em 2004, cerca da metade do faturamento bruto era proveniente das vendas no mercado externo. Dando continuidade ao processo de internacionalização, a empresa consolidou sua operação na Europa, com a criação de uma gerência regional, sediada na Holanda, dois escritórios de vendas na Inglaterra e Holanda e um escritório em Dubai, no Oriente Médio (Perdigão, Relatório anual, 2003: 4). 
A Perdigão chegou ao início do século XXI com um parque industrial somando 13 unidades, ${ }^{14} 18$ centros de distribuição próprios ${ }^{15}$ e mais 10 distribuidores terceirizados. ${ }^{16}$ Passou de frota própria para terceirizada, contando com 500 veículos exclusivos que se responsabilizam pelo transporte nacional e pelas exportações, $80 \%$ das quais acontecem através do Porto de Itajaí (SC).

\section{CONSIDERAÇÕES FINAIS}

A Perdigão é o típico exemplo de empresa que iniciou familiar, com uma gama limitada de produtos, atuando em uma única região, sendo administrada pelos membros das famílias fundadoras, como as descritas por Chandler (1988). Na segunda geração, diversificou sua linha de produtos, ampliou a área de atuação, escolheu e consolidou uma marca, implantou-se no território nacional, iniciou o processo de exportações, superando a fase inicial e tornando-se uma empresa "moderna" e diversificada.

Iniciando suas atividades no oeste catarinense, região agrícola com pequeno mercado local, para crescer e rivalizar com as concorrentes, seria necessário fazer chegar suas mercadorias à região Sudeste (São Paulo e Rio de Janeiro). Para isso não hesitou em montar uma estrutura própria de transporte aéreo, combinado com os caminhões do "Expresso Perdigão". Como suporte à atividade de distribuição, empreendeu a construção de diversas filiais comerciais que lhe permitiram atingir, a partir de São Paulo, todo o mercado nacional.

Quanto ao crescimento, expansão e ocupação do território, a Perdigão permaneceu longo tempo atuando apenas em seu município de origem. Foi só na segunda metade dos anos 1980 que deixou seu Estado para estabelecer-se no Sul, Sudeste e Centro-Oeste, onde construiu plantas industriais e complementou sua rede de distribuição com filiais comerciais próprias ou terceirizadas.

De acordo com a análise de Chandler, deixou de ser uma empresa na qual seus proprietários exerciam todas as funções para se tornar uma firma multidivisional e multiprodutos. Saiu de sua cidade para ocupar não só o mercado nacional, mas também para disputar parcela significativa no mer- 
cado internacional, por via de exportações e escritórios próprios de vendas em diversos continentes.

Para crescer e ganhar posições na lista das 500 maiores, nas décadas de 1970 e 1980 a Perdigão abriu seu capital e fez empréstimos. Esse crescimento rápido trouxe-lhe dois problemas, em parte responsáveis pela venda no início dos anos 1990. O primeiro foi o endividamento a curto prazo, utilizado na busca de recursos para viabilizar a compra e atualização tecnológica das concorrentes adquiridas. Em segundo lugar aconteceu a perda de seu core business, deixando de ser um abatedouro de suínos e aves e moinho de trigo para perder-se em uma série de atividades industriais complexas e nem sempre complementares à atividade inicial.

Aliado aos problemas mencionados, surgiu a passagem do poder da segunda para a terceira geração, quando Saul Brandalise morreu, em 1992. Somando-se problemas de endividamento com excesso de diversificação de atividades e dificuldades administrativas, a Perdigão foi vendida para um pool de acionistas que indicaram tanto o presidente quanto os novos diretores executivos, desvinculados da propriedade das ações. Passava-se de uma administração familiar para uma gestão profissional.

De acordo com a análise de Gersick et al. (1998), a Perdigão conseguiu passar do estágio do "proprietário fundador" para a segunda geração. No momento de transmitir o poder para os herdeiros da terceira geração, a empresa foi vendida, antes de chegar à fase do "consórcio de primos".

A gestão profissionalizada que assumiu após a venda implementou inovações técnicas, novas estratégias de produção e distribuição, e uma logística atualizada, que levaram a empresa a retomar seu espaço no mercado nacional e nas exportações. A nova administração conseguiu dos acionistas uma permanente política de investimentos, aumentando a capacidade instalada e a inovação em produtos, o que fez crescer o número de funcionários, o faturamento bruto e a ocupação do território nacional, tanto com uma ampla rede distribuidora quanto com novos parques industriais.

Nem sempre é assim, mas na Perdigão a equipe de dirigentes profissionais que assumiu a direção após a venda garantiu e aumentou a empregabilidade, ampliou a oferta de produtos, melhorou o market-share, diversificou e ampliou a presença internacional do grupo, aumentou o faturamento e o lucro e garantiu o retorno esperado pelos acionistas. 


\section{NOTAS}

1. http://www.perdigao.com.br/site/?acao=aperdigao\&subacao=timeline. Acesso em: 4 fev. 2005.

2. Para uma descrição detalhada do avanço das empresas agroindustriais nessa região, ver os trabalhos de Dalla Costa (2000), Mior (1992) e Campos (1987).

3. Maiores detalhes a respeito da teoria e da passagem do poder nas empresas familiares podem ser encontrados em Dalla Costa (2006), que resgata as principais discussões atuais sobre o tema e depois apresenta cinco cases de empresas que já passaram pela passagem do poder entre as gerações.

4. Segundo relato de Darcy Ribeiro (1985), o Exército brasileiro, sob o comando do general Setembrino, com tropas de 7 mil homens armados com canhões, metralhadoras e até aviões de bombardeio, assalta, persegue, desaloja e mata, de 1912 a 1916, cerca de 20 mil lavradores pobres que haviam se instalado na fronteira do Paraná com Santa Catarina. Aquela área, sendo de jurisdição contestada pelos dois Estados, não pudera ser entregue aos latifundiários nativos nem às empresas estrangeiras de colonização, o que se faria depois da chacina.

5. A estrada de ferro ligando Itararé (SP) a Marcelino Ramos (RS), passando por União da Vitória (PR), era um projeto ainda do tempo do Brasil Império. Os republicanos o mantiveram como forma de ocupar aquela região e estabelecer definivamente as fronteiras entre os Estados. A ferrovia foi inaugurada em 1910, servindo de ligação entre a região e os grandes centros consumidores: São Paulo e Rio de Janeiro.

6. Saul e Elejalde tiveram três filhos: Flávio Brandalise (1939), Maria Odete Brandalise (1943) e Saul Brandalise Junior (1949). Tanto Flávio como Saul Junior mais tarde o ajudaram na administração da Perdigão até início da década de 1990, quando, após a morte de Saul Brandalise, venderam a empresa, dedicando-se a outras atividades (Brandalise, 1982, e material da Perdigão).

7. O Município de Videira foi instalado no dia $1^{\circ}$ de março de 1944, tendo Ângelo Ponzoni como primeiro prefeito eleito. No final do seu mandato, no início da década de 1950, transferiu-se para São Paulo, onde permaneceu como principal responsável pela comercialização dos produtos Perdigão, no mercado nacional e internacional, até meados dos anos 1970 .

8. Para termos uma idéia da diferença de volume de abates, no maior abatedouro do Brasil, situado em Toledo e pertencente à Sadia, no início de 1999 eram abatidos 360 mil frangos por dia (entrevista com dirigente da Sadia, em Curitiba, 28 de março de 1999). Esse volume de abates foi superado pelo frigorífico de Dois Vizinhos, também da Sadia, no sudoeste do Paraná, que, ampliado, passou a abater 500 mil frangos por dia a partir de 2005.

9. Na ocasião estavam à frente da direção do grupo: Saul Brandalise (diretor-superintendente), Antonio Pasqualli (diretor comercial), André David Brandalise (diretor comercial), Achyles Emílio Ponzoni (diretor-gerente) Euclides Anastácio Brandalise (diretor-tesoureiro), Luis Kellermann (diretor industrial), Pedro Ponzoni (diretor- 
assistente) e Giacomo Pasqual, Ângelo Leoni e Orlando Zardo (diretores) (Tassara e Scapin, 1996: 68).

10. Avós são as aves que detêm o segredo genético da raça e servem para colocar os ovos que geram as matrizes. Estas, por sua vez, geram os pintinhos que serão criados pelos produtores rurais e depois abatidos nos frigoríficos.

11. Somando-se o total de ações ordinárias e preferenciais, ficou assim distribuído o controle acionário da Perdigão: Previ - Caixa Previdenciária do Banco do Brasil, 15,03\%; Fundação Telebrás de Seguridade Social - Sistel, 15,03\%; Petrus - Fundação Petrobras de Seguridade Social, 12,17\%; Real Grandeza Fundação de APAS, 9,74\%; Weg Motores Ltda., 8,80\%; União de Comércio e Participações Ltda.; 3,88\%; Previ - Banerj, 2,80\%; BNDES Participações S.A., 2,01\%; Valia - Fundação Vale do Rio Doce, 1,73\%; Telos Fundação Embratel de Seguridade Social, 1,57\%; Bradesco Turismo S.A., 1,12\%; Fundo de Participação Social, 0,35\%; Banco Bradesco, 0,10\%; outros, 16,66\% (Perdigão, Relatório anual, 1994).

12. Em função da falta de investimentos produtivos nas nove unidades de processamento de carnes no início da década de 1990, a Perdigão (que teve um faturamento bruto de US\$ 628,3 milhões) viu sua participação no mercado cair de 19\% para 16,4\% (O Globo, Caderno de Economia/Negócios, 2 de maio de 1995, p. 22).

13. Nem sempre, no entanto, uma presença forte no mercado externo é vantajosa. Em 2005 e 2006, em função de problemas com a "gripe aviária", o consumo de derivados de aves caiu, prejudicando o desempenho financeiro da Perdigão, que voltou a investir no mercado interno.

14. As unidades industriais da Perdigão estão localizadas em Santa Catarina: duas em Capinzal e Videira, uma em Rio Verde; uma em Herval d'Oeste, Lages e Salto Veloso; em Goiás e no Rio Grande do Sul: três em Marau e uma em Serafina Corrêa e no Paraná, com uma unidade em Carambeí (Perdigão, Relatório anual, 2003: 8).

15. Os centros de distribuição próprios estão localizados em Bauru, Campinas, Cubatão (SP), Belo Horizonte (MG), Brasília (DF), Curitiba e São José dos Pinhais (PR), Florianópolis e Videira (SC), Fortaleza (CE), Manaus (AM), Porto Alegre (RS), Recife (PE), Rio de Janeiro (RJ), Rio Verde (GO), Salvador (BA), Vitória (ES).

16. Os distribuidores terceirizados encontram-se em Apucarana (PR), Belém (PA), Campos dos Goitacazes e Nova Friburgo (RJ), Cuiabá (MT), Juiz de Fora (MG), Porto Velho e Vilhena (RO), Presidente Epitácio (SP) e Rio Branco (AC). Dessa forma, contando com os centros próprios de distribuição e os terceirizados, a Perdigão possui uma estrutura de distribuição que lhe permite atender a todo o território nacional.

\section{REFERÊNCIAS BIBLIOGRÁFICAS}

APA - Associação Paulista de Avicultura (1995) Revista Aves \& Ovos, ano XI, n. 4: Guia Aves \& Ovos: referência e indicadores para seus negócios, fev.

ARASHIRO, O. (1989) A história da avicultura do Brasil. São Paulo: Gessulli Editores. 
BRANDALISE, S. (1982) Retrato de um homem. Videira: Perdigão S.A. Comércio e Indústria.

CAMPOS, I. (1987) Os colonos do rio Uruguai. Relações entre pequena produção e agroindústria no oeste catarinense. Campina Grande. Dissertação de Mestrado.

CEAG - Centro de Assistência Gerencial de Santa Catarina (1978) Análise do sistema de integração agroindustrial em suínos e aves em Santa Catarina. Florianópolis: CEAG.

CHANDLER, A. (1972) Stratégies et Structures de L'entreprise. Paris: Les Éditions d'Organisation. - (1988) La Main Visible des Managers. Paris: Economica.

(1992) Organisation et Performance des Entreprises. Tome 1 - Les USA 1880-1948. Paris: Les Éditions d'Organisation.

DALLA COSTA, A. J. (1993 ) "O grupo Sadia e a produção integrada: o lugar do agricultor no complexo agroindustrial”. Dissertação de Mestrado. Curitiba: UFPR.

_ (2000) "L'agro-industrie brésilienne contemporaine: innovations organisationnelles et transformations technologiques dans l'aviculture”. Villeneuve d'Ascq: Presses Universitaires du Septentrion.

— (2002) "Sadia, Perdigão e Hermes Macedo: nascimento, expansão e crise por ocasião da passagem do poder nas empresas familiares". In: A. M. Kirschner., E. R. Gomes., P. Cappellin (orgs.). Empresa, empresários e globalização. Rio de Janeiro: Relume Dumará, 2002. p. 153-170.

— (2006) Sucessão e sucesso nas empresas familiares. Curitiba: Juruá.

DEAN, W. (1971) A industrialização de São Paulo: 1880-1945. São Paulo: Difel.

DESOUZART, O. (1994)“O quo vadis da indústria avícola para o ano 2000: Avanço no consumo de carnes e a perspectiva do mercado internacional”. In : Anais da Conferência Apinco 1994 de Ciência e Tecnologia Avícolas. Campinas, p. 151-157.

GERSICK, K. E., HAMPTON, D. M. M., LANSBERG, I. (1998 ) “De geração para geração”. Ciclos de vida das empresas familiares. São Paulo: Negócio Editora.

GIROTTO, A. F., MIELE, M. (2004) "Situação atual e tendências para a avicultura de corte nos próximos anos”. In: Anuário 2005 da Avicultura Industrial. São Paulo: Gessuli, ano 96, n. 11, ed. 1.129, p. 20-28.

http: //www.abef.com.br. Associação Brasileira de Exportadores de Frangos. Várias consultas nos últimos anos.

http: //www.apa.com.br. Associação Paulista de Avicultura. Várias consultas nos últimos anos.

http: //www.asgav.com.br. Associação Gaúcha de Avicultura. Várias consultas nos últimos anos.

http: www.perdigao.com.br/historia.htm. Várias consultas nos últimos anos.

INFORMANAB (1994-1995) "Informativo da Associação Nacional dos Abatedouros Avícolas".

MARTINS, I. G. da S., MENEZES, P. L. de, BERNHOEFT, R. (org.). “Empresas familiares brasileiras”. Perfil e Perspectivas. São Paulo: Negócio Editora, 1999. 
MIOR, L. C. (1992) “Empresas agroalimentares, produção agrícola familiar e competitividade no complexo carnes de Santa Catarina”. Dissertação de Mestrado. Rio de Janeiro: UFRJ.

PERDIGÃO. Relatório anual. Vários anos. (1994) Perdigão 60 anos.

RIBEIRO, D. (1985) Aos trancos e barrancos: como o Brasil deu no que deu. Rio de Janeiro: Guanabara.

RIZZI, A. (1993) “Mudanças tecnológicas e reestruturação da indústria agroalimentar: o caso da indústria de frangos no Brasil”. Tese de doutorado. Campinas: Unicamp.

SILVEIRA P. M. (1990) Produtor e agroindústria: consensos e dissensos. O caso de Santa Catarina. Florianópolis, Santa Catarina: Editora da UFSC.

TASSARA, H., SCAPIN, A. (1996) Perdigão uma trajetória para o futuro. Videira: Empresa das Artes.

TEDESCO, J. C. (1992) “A produção familiar e a agroindústria”. Dissertação de Mestrado. Porto Alegre: UFRGS. 